\title{
Monotheistische Denkfiguren in der Spätantike
}

\author{
Hrsg. v. Alfons Fürst, Luise Ahmed, Christian Gers-Uphaus u. Stefan Klug
}

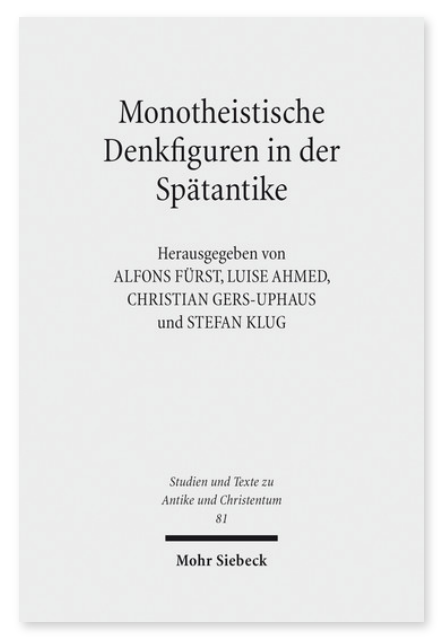

2013. VIII, 293 Seiten. STAC 81

ISBN 978-3-16-152823-1

DOI 10.1628/978-3-16-152823-1

eBook PDF $89,00 €$

ISBN 978-3-16-152385-4

fadengeheftete Broschur 89,00€
Monotheistische Gottesvorstellungen haben über einen langen Zeitraum hinweg das Religionsverständnis des christlich geprägten Europa beherrscht. Für die frühen Christen gehörte das vom Judentum übernommene monotheistische Gottesbild elementar zu ihrem Selbstverständnis. Aus dem Blick gerät dabei, dass auch in der polytheistischen antiken Kultur monotheistische Tendenzen zu beobachten sind, die in der Forschung unter dem Phänomen 'paganer Monotheismus' diskutiert werden. Die Beiträge des vorliegenden Bandes analysieren monotheistische Konzepte, Argumentationen und Modelle anhand ausgewählter Werke spätantiker Autoren. Dabei werden wichtige Aspekte monotheistischer Denkfiguren erörtert, in denen die Entwicklung des komplexen antiken Monotheismus sowohl in christlichen als auch in 'paganen' Texten Ausdruck gefunden hat.

\section{Inhaltsübersicht}

Christian Gers-Uphaus/Stefan Klug: Einleitung: Die spätantike Debatte über den Monotheismus - Alfons Fürst: Die Rhetorik des Monotheismus im Römischen Reich. Ein neuer Zugang zu einem zentralen historischen Konzept - Luise Ahmed: Das monotheistische Gottesbild als Konversionsmotiv? - Christian Müller: Aggressiver Polytheismus? Monotheismus als (k)ein Thema in christlichen Märtyrerakten - Christian Gers-Uphaus: Rhetorik des Monotheismus in der Oratio ad Graecos Tatians Andrea Villani: Tertullianische Variationen zum Thema Monotheismus - Christoph Bruns: Überlegungen zum Subordinatianismus in der Trinitätslehre des Origenes - Jochen Sauer: Naturrechtsdiskurs und Monotheismus. Denkfiguren ciceronischer Prägung in Laktanz' Argumentation für den Monotheismus - Sara Stöcklin-Kaldewey: Göttliche Hierarchie und Aufgabenteilung bei Kaiser Julian - Nicola Hömke: Pater rerum und dreieiniger Gott. Die Prädikation des einen Gottes in den Versus paschales des Ausonius - Therese Fuhrer: Augustins Modellierung des manichäischen Gottesbildes in den Confessiones - Peter Lötscher: Varro in der lateinischen Apologetik und der pagane Monotheismus - Franco Chiai: Die Ortsgebundenheit des Göttlichen bei Macrobius - Ilinca Tanaseanu-Döbler: Einheit des Göttlichen bei Proklos

Alfons Fürst Geboren 1961; 1996 Promotion (Dr. phil.); 1998 Habilitation (Dr. theol. habil.); 1998-2000 Professor für Kirchengeschichte in Bamberg; seit 2000 Professor für Alte Kirchengeschichte, Patrologie und Christliche Archäologie in Münster; 2010-11 Fellow am Department of Classics in Princeton; 2017-18 Fellow am Institute for Advanced Studies in Jerusalem.

Luise Ahmed Geboren 1985; seit 2009 wissenschaftliche Mitarbeiterin am Seminar für Alte Kirchengeschichte der WWU Münster.

Christian Gers-Uphaus 2012 Diplom in Katholischer Theologie, 2015 Master in Antike Kulturen des östlichen Mittelmeerraums.

Stefan Klug Geboren 1979; 2010-13 Stipendiat der Bischöflichen Studienförderung Cusanuswerk; seit 2013 Referendar im Schuldienst (Geschichte, Kath. Religionslehre).

Jetzt bestellen:

https://mohrsiebeck.com/buch/monotheistische-denkfiguren-in-der-spaetantike-9783161528231?no_cache=1 order@mohrsiebeck.com

Telefon: $+49(0) 7071-923-17$

Telefax: $+49(0) 7071-51104$ 